\title{
Twenty five years of case finding and audit in a socially deprived community
}

Julian Tudor Hart, Colin Thomas, Brian Gibbons, Catherine Edwards, Mary Hart, Janet Jones, Margaret Jones, Pam Walton

\begin{abstract}
Objective-To evaluate audit and case finding (whole population care) in a community over 25 years.

Design-Contemporary screening for and audits of care of chronic disease and risk factors; retrospective review of computerised practice records; and comparisons of mortality and social indices with neighbouring communities.

Setting-One general practice in Glyncorrwg, West Glamorgan.

Subjects -1800 people registered with the practice in 1987 and 558 people who died from 1964 to 1987, whose records had been retained.

Main outcome measures - Detection of high blood pressure, smoking, airways obstruction, obesity, diabetes, and alcohol problems in adults aged 20-79; prevalence of smoking in this population and in hypertensive and diabetic groups; age standardised mortality ratios in relation to indices of social deprivation.
\end{abstract}

Results-In the population aged 20-79 (1207 patients) $249(21 \%)$ had peak expiratory flow rate less than $50 \%$ of expected value or which improved by $15 \%$ or more with an inhaled $\beta$ agonist, $207(17 \%)$ had body mass index at or over $30 \mathrm{~kg} / \mathrm{m}^{2}, 118(10 \%)$ had untreated mean arterial pressures greater than $159 / 104 \mathrm{~mm} \mathrm{Hg}$ (three readings), $80(7 \%)(65$ (16\%) men, 15 (4\%) women) had recognised alcohol problems, and $35(3 \%)$ had diabetes. The proportion of men aged 20-64 who said they smoked fell from $61 \%(290 / 476)$ in $1968-70$ to $36 \%(162 / 456)$ in 1985 whereas that of women who smoked was unchanged $(43 \%, 187 / 436 v 42 \%, 190 / 448$ respectively). In 116 screened hypertensive patients group mean blood pressure fell from $186 / 110 \mathrm{~mm} \mathrm{Hg}$ before treatment to $146 / 84 \mathrm{~mm} \mathrm{Hg}$ at 1987 audit, as did the proportion of smokers $(56 \% v 20 \%$ ), but body mass index and total cholesterol concentration showed no significant change. In 34 diabetic patients mean blood pressure and the proportion of smokers fell $(171 / 93 \mathrm{~mm} \mathrm{Hg} v$ $155 / 81 \mathrm{~mm} \mathrm{Hg} ; 44 \%$ v 12\%). The age standardised mortality ratio in 1981-6 was lower than in a neighbouring village without a developed case finding programme (actual to expected deaths $\angle 65=21$ to 22 in Glyncorrwg, $\mathbf{4 8}$ to 30 in control village).

Conclusions-Whole population care through organised case finding and audit is feasible but only with a labour intensive approach combining accessibility, flexibility, and continuity, as well as a planned and structured approach, which requires substantial expansion of staff numbers and assiduous recording. It may reduce risks for at least some high risk groups. Despite their shortcomings the available data are consistent with the hypothesis that whole population care helps reduce mortality. Incentives in the new contract, which encourage the uncritical development of structured process, may diminish health outputs.

\section{Introduction}

For health as for commodity production, absolute growth conceals relative decline. By 1980 the United Kingdom ranked highest in the European Community and Scandinavia for all causes mortality in men and women aged 45-64.

The close and causal relation between mortality, morbidity, and social class for all major cause ${ }^{23}$ is the main explanation for the exceptionally high mortality and morbidity in Scotland, Northern Ireland, and parts of northern England and south Wales, for all causes as well as for coronary disease. As inequalities in wealth have grown so have inequalities in sickness and death. ${ }^{4}$ These differences are compounded by increasing inequalities in clinical resources available to deal with them: fed by the market, the inverse care law thrives. As predicted by thoughtful economists, ${ }^{67}$ the new general practitioner contract accelerates previous trends, promoting investment in high earning practices serving affluent areas, where care is easier, ${ }^{8}$ and discourages investment in practices whose earnings are lowest, whose patients are poorer and sicker, whose costs are higher, and whose clinical work is more difficult. ${ }^{9}$

As the Cardiff ${ }^{10}$ and Ipswich ${ }^{11}$ studies of non-insulin dependent diabetes exemplified, routine management of chronic disease in general practice compares badly with routine hospital outpatient practice. For the general population, the rule of halves ${ }^{12}$ still applies, not only for hypertension but also probably for other health risks in which demands relate little to needs. As an order of magnitude, half of all specific health needs are not known, half of those known are not helped, and half the help given is not effective.

This paper describes an attempt, sustained over 25 years, to contain or reverse these trends in one small community by assessing health variables throughout the registered practice population.

Patients and methods

POPULATION AND SOCIAL INDICES

Our data are derived from clinical records of 1800 people registered with the Glyncorrwg practice in 1987 and 558 people who died from 1964 to 1987, whose records were retained. During that time 1108 patients left the practice through out-migration, and data on them are not included. Data from 450 patients lost in 1983 through secession of a partner are included up to that time. An age-sex register was set up in 1966 after a private census and has been updated weekly since. Male occupations were listed in 1966: they showed that $6 \%$ of the population was in social classes I and II 
(England and Wales 12\%); 5\% in class III non-manual $(14 \%)$; and $89 \%$ in classes III manual, IV, and V manual $(64 \%)$.

Though having the lowest percentage of the population aged 65 or more in West Glamorgan, the three wards of the Upper Afan Valley, Glyncorrwg, Cymmer, and Gwynfi, are among the worst $5 \%$ of all 800 wards in Wales in terms of percentage permanently sick and disabled, percentage car ownership, and percentage unemployed. ${ }^{13}$ Census data for the Afan Valley showed $8 \%$ more inpatients, $21 \%$ more outpatients, and $8 \%$ more contacts with general practitioners than for Wales as a whole. ${ }^{1+}$ Though data are not available for 1961, when the senior author (JTH) began work in the Afan Valley, the relative social ranking has probably changed little since then. Male unemployment rose from $8 \%$ in 1965 to a sustained $40 \%$ or more from 1980 to 1987, after collapse of the coal industry and rationalisation of steel production, but female employment has increased substantially.

WORKLOAD, CASE FINDING, RECORDS, AND ORGANISATION

From 1964 to 1972 annual consultation rates in Glyncorrwg ran at a steady $5 \cdot 3$ contacts per person registered, $11 \%$ lower than the mean rate for other coal mining practices in south Wales but more than twice that for 114 general practitioners participating in the 1970-2 national morbidity survey. ${ }^{15}$ By 1987 the rate still stood at $4 \cdot 7$ contacts per person registered.

By 1968 we were able to meet our first prioritynamely, providing an adequate demand led service - and could begin systematic search for the health needs of the practice population. Between 1968 and 1970 we screened $98 \%$ of our population aged $20-64$ for high blood pressure, ${ }^{16} 17$ mainly by case finding within consultations but supplemented by active call up and, finally, by home visits. Similar but less vigorous approaches were later applied to older patients and other risks for coronary heart disease, stroke, and other major outcomes: cigarette smoking, serum tota cholesterol concentration, obesity, diabetes, airways obstruction, and alcohol problems. Finally, we looked at the recorded run up to death in 500 patients who died from 1964 to $1985^{18}$ for evidence of errors and omissions by patients and staff. ${ }^{19}$.

Our aim was to improve health in the whole registered population by identifying treatable problems at an early, often presymptomatic stage, and to learn from our mistakes by looking for them systematically a repeated cycle of case finding and audit. The policy was to use demand led patient contacts proactively by expanding ordinary consultations, ${ }^{20}$ building a profile of information relevant to anticipatory health care and using this to track progress. We developed and adapted our own protocols, based on our own experience and published reports, mainly from epidemiology, on similar lines to those of Kark in Jerusalem..$^{21}$

This proactive policy depended on practice organisation, teamwork, and structured records. The health authority seemed unable to understand that staff continuity was essential for high compliance in a working class population and that staff would learn only from peers with experience at the coal face rather than managerial experience. We therefore had to employ and train our own staff. We converted our Lloyd-George records to A4 records in 1977, entering retrospective histories of major events for all patients at an estimated cost of 600 hours of mostly medical staff time. Computerisation in 1988-9 (after the audits reported in this paper) took a further 800 hours of staff time. Audit of this kind was previously impossible without substantial staff time additional to the two whole time equivalents available under the 1966 contract, and we succeeded only with help from
Medical Research Council staff. Once completed, computerisation should make such work possible for practices employing staff at the same rate, but start up requirements will be much greater and must include a large investment of medical time to establish a clinically accurate database. This cannot safely be done by staff entering terms they cannot understand, interpret, or correct; if non-medical staff are used they must have clinical experience and substantial extra training.

\section{Results}

DETECTING HEALTH NEEDS

Table I shows the needs disclosed by systematic search, in terms of cases found at any time in the population aged 20-79 in 1987. We used standardised criteria for diagnosis. Peak flow rates were generally measured only in smokers and people with respiratory symptoms. Though we now strongly agree with the need to ask about alcohol intake routinely in all patients aged 16 or over,,$^{22}$ we only began to apply this policy in the 1980s, and data are still incomplete. We had no standard criteria for labelling alcohol problems, only a high index of suspicion with frequent measurements of $\gamma$ glutamyl transferase activity, mean corpuscular volume, and casual blood alcohol concentration. A self assessed questionnaire on alcohol consumption applied independently to 283 randomly sampled men at Glyncorrwg as part of a Medical Research Council general practitioner research framework study showed that $14 \%$ consumed 41 units a week or more, roughly confirming our suspect rate of $16 \%$, and above the $12 \%$ mean for all framework practices. ${ }^{23}$ Serum cholesterol concentration was generally measured only in hypertensive patients and diabetic patients, heavy smokers, and patients with established arterial disease or with unfavourable family histories, jointly amounting to $30 \%$ of men and $14 \%$ of women.

TABLE I-Health needs disclosed by systematic case finding in 1207 patients aged 20-79, Glyncorrwg, 1989 -

\begin{tabular}{|c|c|c|c|c|}
\hline & No & & $\%$ & $\begin{array}{c}\% \text { No } \\
\text { data }\end{array}$ \\
\hline Current smokers & 431 & & 36 & 4 \\
\hline $\begin{array}{l}\text { Fixed or reversible airways obstruction } \\
\text { (peak flow rate }<50 \% \text { expected value or } \\
\text { increasing by } \geqslant 15 \% \text { after inhaled } \\
\text { salbutamol) }\end{array}$ & & & & \\
\hline salbutamol) & 249 & & 21 & $\star$ \\
\hline Body mass index $>30 \mathrm{~kg} / \mathrm{m}^{2}$ & 207 & & 17 & 19 \\
\hline $\begin{array}{l}\text { Pretreatment mean arterial pressure } \\
>159 / 104 \mathrm{~mm} \mathrm{Hg} \text { (three readings) }\end{array}$ & 118 & & 10 & 4 \\
\hline Recognised alcohol problem & 80 & & 7 & $\star$ \\
\hline Men & & 16 & & \\
\hline Women & & 4 & & \\
\hline Serum total cholesterol $>6.5 \mathrm{mmol} / \mathrm{l}$ & 92 & & 8 & $\star$ \\
\hline Diabetes & 35 & & 3 & ^ \\
\hline
\end{tabular}

*Search in subsets only.

Though all these groups overlap, the potential follow up workload resulting from the ascertainment of these health needs is both large and cumulative. Finding initial values - the case finding process itselfis relatively easy in a stable population. The real challenge is follow up and maintaining low default rates and high compliance in subsequent management.

\section{RISK CONTROL IN TARGET GROUPS}

In order to achieve our aim we had to prioritise. We began with what seemed in the late 1960s and early 1970 s to be the most dangerous but also most tractable problems: high blood pressure and smoking. We began to tackle diabetes systematically in the late 1970 s, airways obstruction in the early 1980s, alcohol problems in the mid-1980s, and hyperlipidaemias erratically from 1968 onwards, with our hopes being alternately raised by published reports and dashed by experience. Despite this proactive activity we were 
still mainly occupied with symptomatic illness. We addressed smoking throughout the population because we thought we knew what to do. We did not know, and still do not know, how to change blood pressure throughout the population, only how to control extreme deviance. A heroic search for ways to shift mean pressure through double blind randomised trials of sodium restriction was convincingly unsuccessful. ${ }^{2+26}$

Our most easily identified and managed target groups were hypertensive and diabetic patients, and we believed that at least some of the educational work done in these groups would influence our general population. Our aims were to control not only high blood pressure and blood glucose concentration but also all major cardiovascular risks in these high risk groups. Tables II and III show the results at our last audit in May 1989. We adapted the "three box" strategy evolved by John Coope ${ }^{27}$ for managing hypertension in populations, with decision points initially derived from Hamilton and colleagues' $1964^{28}$ and the Veterans Administration's 1970 trials, ${ }^{29}$ subsequently reinforced by a conservative interpretation of the MRC mild hypertension trial. ${ }^{3031}$ This divides the whole adult screened population into box 1 , with subjects with mean untreated diastolic pressures $>104 \mathrm{~mm} \mathrm{Hg}$ offered treatment and review every three months: box 2 , subjects with mean untreated diastolic pressures 90-104 mm Hg generally not treated, unless there is evidence of diabetes or a family history of stroke, and reviewed annually; and box 3, subjects with mean diastolic pressures $<90 \mathrm{~mm} \mathrm{Hg}$ reviewed every five years. The figure shows the logistics of this process over its first 13 years for a cohort of 912 men and women aged 20-64 in 1968-70. In both tables and the figure all groups are shown on an intention to treat basis, including those who either failed to start or dropped out of treatment.

Group shifts in blood pressure and smoking were achieved within a year or two once management was reorganised on a clinic basis, with active recall and recognition of default..$^{32}$ There was virtually no net shift in obesity or blood cholesterol concentration. Some increase in both would be expected with age so

TABLE II -Mean values for risk factors in 116 screened hypertensive patients before treatment and in 1989

\begin{tabular}{lcc}
\hline Risk factor & $\begin{array}{c}\text { Mean value } \\
\text { before treatment }\end{array}$ & $\begin{array}{c}\text { Mean value } \\
\text { in } 1989\end{array}$ \\
\hline Blood pressure $(\mathrm{mm} \mathrm{Hg})$ & $186 / 110^{\star}$ & $146 / 84 \dagger$ \\
No $(\%)$ smokers & $65(56)$ & $23(20)$ \\
Body mass index $\left(\mathrm{kg} / \mathrm{m}^{\prime}\right)$ & $28 \cdot 5$ & $28 \cdot 0$ \\
Serum total cholesterol $(\mathrm{mmol} / \mathrm{l})$ & $6 \cdot 2$ & $6 \cdot 1$ \\
\hline
\end{tabular}

$\star$ Mean of last three recorded measurements before treatment. tMean of last three recorded measures available in 1989.

TABLE III-Mean values for risk factors in 34 diabetic patients before treatment and in 1989

\begin{tabular}{|c|c|c|}
\hline Risk factor & $\begin{array}{c}\text { Mean value } \\
\text { before treatment }\end{array}$ & $\begin{array}{l}\text { Mean value } \\
\text { in } 1989\end{array}$ \\
\hline Glycated haemoglobin (\%) & Not available & $8 \cdot 8$ \\
\hline Blood pressure $(\mathrm{mm} \mathrm{Hg})$ & $171 / 93$ & $155 / 81$ \\
\hline No $(\%)$ smokers & $15(44)$ & $4(12)$ \\
\hline Body mass index $\left(\mathrm{kg} / \mathrm{m}^{\prime}\right)$ & $31 \cdot 5$ & $31 \cdot 4$ \\
\hline
\end{tabular}

TABLE IV-Number (percentage) of smokers in Glyncorrwg men aged 20-64, 1968-70 and 1985 according to personal statemenis (verified for 1985 only $)^{\star}$

\begin{tabular}{lccc}
\hline & $\begin{array}{c}1968-70 \\
\text { statements }\end{array}$ & $\begin{array}{c}1985 \\
\text { statements }\end{array}$ & $\begin{array}{c}1985 \\
\text { verified statements }\end{array}$ \\
\hline Smokers & $290(61)$ & $162(36)$ & $192(42)$ \\
Non-smokers & $176(37)$ & $289(63)$ & $230(50)$ \\
No data & $10(2)$ & $5(1)$ & $35(8)$ \\
\hline
\end{tabular}

^By determination of urinary cotinine concentration.

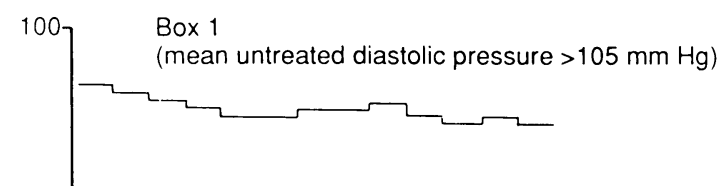

Box 2 (mean diastolic pressure 90-104 mm Hg)
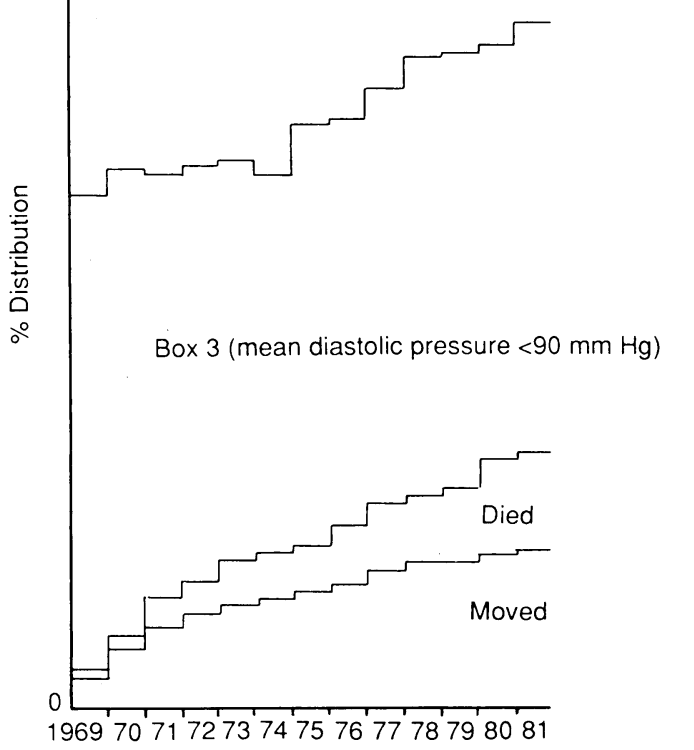

Year

Percentage distribution of management groups, 1968-81, for cohort of 476 men and 436 women aged 20-64 at entry

TABLE $\mathrm{v}-$ Number (percentage) of smokers in Glyncorrwg women aged 20-64, 1968-70 and 1985 according to personal statements (verified for 1985 only) ${ }^{\star}$

\begin{tabular}{lccc}
\hline & $\begin{array}{c}1968-70 \\
\text { statements }\end{array}$ & $\begin{array}{c}1985 \\
\text { statements }\end{array}$ & $\begin{array}{c}1985 \\
\text { verified statements }\end{array}$ \\
\hline Smokers & $187(43)$ & $190(42)$ & $199(44)$ \\
Non-smokers & $227(52)$ & $233(52)$ & $224(49)$ \\
No data & $22(5)$ & $25(6)$ & $30(7)$ \\
\hline
\end{tabular}

^By determination of urinary cotinine concentrations.

TABLE VI - Social deprivation ranking in 55 wards of West Glamorgan, age standardised mortality ratios, ${ }^{\star}$ and actual and expected deaths in subjects aged <65, Aber/Blaengwynfi and Glyncorrwg, 1981-6

Aber/Blaengwynfi Glyncorrwg

\begin{tabular}{lcc}
\hline Townsend deprivation score & $4 \cdot 83$ & 3.91 \\
Rank/55 wards & $51 \cdot 55$ & $48 \cdot 55$ \\
Standardised mortality ratio: & $135 \cdot 6$ & $97 \cdot 6$ \\
$\quad$ All ages & $160 \cdot 1$ & 93.5 \\
$\quad<65$ & 48 & 21 \\
Deaths at age $<65:$ & 30 & 22 \\
$\quad$ Actual & 30 \\
$\quad$ Expected & & \\
\hline
\end{tabular}

${ }^{\star}$ England and Wales $=100$

the absence of a change is less complete than it seems. In diabetic patients (table III), though no pretreatment values for glycated haemoglobin were available, glycaemic control was good for the group as a whole, and so were blood pressure and control of smoking. Little was achieved in controlling obesity, a main objective in this group.

\section{RISK CONTROL IN THE GENERAL POPULATION}

Targeting the population was more difficult. Hypertensive patients and diabetic patients have disease labels, implying exceptional risks which justify exceptional behaviour. In Wales the general middle aged population is mostly unhealthy by physiological standards $\mathrm{s}^{33}$ but has (and should have) none of the attributes of the sick role which reinforce medical authority. Tables IV and V show stated smoking habits in men and women in 1968 and 1985, as well as the 
results of urine continine testing in 1985 only. Achieving a reduction in smoking in the general population was more difficult than in the target groups of hypertensive and diabetic patients. Our local campaign began in 1968 and was well established before the launch of the Heartbeat Wales campaign in $1985,{ }^{3+}$ but obviously all our work was done against a background of complex social pressures for and against smoking. Most change in smoking in our male population occurred before 1975, suggesting that the $5 \%$ of smokers who give up for a year or more after cursory advice from family doctors ${ }^{35}$ are not cumulative; those who are easily persuaded respond quickly, but in many others nicotine seems to induce dependence similar to that with other dangerous drugs, probably requiring more counselling and support than doctors can give. We achieved no net reduction in female smoking; reductions in older women were balanced by recruitment in younger women, in line with national trends in working class subjects. The tobacco industry and its advertisers have successfully identified smoking with independence, personal coping strategies, and slim figures.

\section{MORTALITY}

In a study of small area statistics in West Glamorgan Thomas and Kaul showed that differences in mortality in 1981-3 between the three wards of the Upper Afan Valley (Glyncorrwg, Cymmer, and Aber/Blaengwynfi) did not coincide with social differences. ${ }^{15}$ Though all were in the bottom $5 \%$ of the distribution for the Townsend social deprivation score,${ }^{36}$ in terms of age standardised mortality ratios under age 65 , Glyncorrwg ranked fourth in the distribution for all 55 wards in West Glamorgan whereas Aber/Blaengwynfi and Cymmer ranked 32nd and 36th respectively. This was poor evidence of a real difference because of the small number of deaths under age 65 in the three years studied: 38 in Cymmer, 20 in Gwynfi, and eight in Glyncorrwg. For deaths at all ages Cymmer must be excluded from analysis because it contains two homes for the elderly. However, when deaths at all ages during 1981-6 are included the difference between Aber/Blaengwynfi and Glyncorrwg still holds, as table VI shows. Aber/Blaengwynfi had demand led care in a traditional pattern until 1980 . Though broadly similar strategy for proactive care was then gradually introduced, as in Glyncorrwg, it took many years and much work to meet high demands well enough to make space for innovation, and it is unlikely that new methods of work had much impact before 1985 .

Weak though it is, this evidence is consistent with the hypothesis that the cycle of planned innovation, audit, and revision may have reduced mortality, despite serious errors. ${ }^{19}$ Though both wards ranked low on the Townsend score, such differences as there were favoured Glyncorrwg, so even if differences in mortality are new and sustained they might have been caused entirely by differences in social deprivation, which seem to operate at all levels. ${ }^{+}$

\section{Discussion}

Most of our measurements were obtained during consultations prompted by patient demand, and we generally found that this is the best way to approach working class patients. This view and its converse (that working class people at high risk respond poorly to health promotion clinics) have been generally endorsed by others, ${ }^{37-40}$ some working in more difficult conditions. ${ }^{9+1}$

Clinics are more important for follow up than for screening. Continuing care is more difficult and demanding than ascertainment, a characteristic often overlooked by planning authorities, though bound to grow as case finding continues, ${ }^{+2}$ until it eventually levels off as we escape the rule of halves. Protected time, delegation to nurses and specialised training for them, recognition of defaulters, and shared learning in groups of patients with common problems, all of which are essential to controlling chronic conditions, are possible only with clinic organisation. ${ }^{43}$ Without clinics there is a steady loss of patients from unperceived drop out, because instead of discussing a list of nonattenders at the end of an evening session, staff are relieved that the clinic did not last even longer. Drop out from hypertension programmes in the United States has generally varied between $20 \%$ and $50 \%$ a year. ${ }^{+}$With drop outs defined as patients without contact for four months or more, our drop out rate fell below $10 \%$ by 1981 and remained about that level to $1987 . .^{42}$ Drop out is minimised by personal care with continuity of staffing within a planned structure including regular review of defaulters.

In our experience clinics are a necessary means, but if delegated out of sight and mind they soon degenerate to irrelevant ritual. They are essential for verified attendance, monitoring, and active recall for hypertensive patients and diabetic patients. We found that other cardiovascular risks, airways obstruction, epilepsy, and alcohol problems could be handled more effectively by extending consultation time, including referral to a practice nurse.

Rather than the average five minutes available for each consultation in 1973, Buchan and Richardson concluded that patients needed and deserved an average of 10 minutes with their family doctor..$^{45}$ Fifteen years later and fortified by evidence that what is lost in short consultations is precisely the proactive, need-seeking component of care, Morrell still had to plead for 10 minute consultations. ${ }^{4647}$

Mean consulting time in Glyncorrwg increased slowly from seven minutes in 1965 to eight minutes in 1970 and 10 minutes in 1987. Representative studies of general practice suggest that it is nearer seven than 10 minutes for $90 \%$ of patients, ${ }^{48}$ and even this may fall if the new contract encourages larger lists. ${ }^{49}$ Shorter consultations seem to require a more authoritarian approach, ${ }^{50}$ which is unsuited to health promotion. The contract has made health promotion clinics into sources of income, ends rather than means. In West Glamorgan before the new contract there were about 10 health promotion clinics a week; now there are 315 , roughly one for each general practitioner, at an extra cost of $£ 73100$ a year in sessional fees alone. At the same time the Department of Health has ruled that systematic case finding through expanded consultations, the only method supported by evidence or experience, will not attract health promotion payments. Health promotion is becoming detached from continuing care ${ }^{51}$ and growing at the expense of the natural and necessary priority for sick people which is the basis for credibility of doctors and nurses to the public. ${ }^{52}$

Our policies in Glyncorrwg were neither conceived nor applied quickly: it took years to work them out and more to apply them, and even then they were revised several times after audit. If this was true for the care of 1800 people known personally to planners living in the community they served, national plans hastily devised and unimaginatively imposed on 65 million people seem unlikely to succeed without more attention to published experience and either major revision or recognition that no pay structure can itself ensure clinical integrity, which depends on an entirely different set of incentives.

As medical science advances clinical medicine will move back from end stage disease to its origins, depending less on symptoms to prompt clinical activity. Asymptomatic need is an unknown territory, in which mistakes are inevitable, but they should at least be 
errors of science rather than excesses of trade. Neither sticks nor carrots can improve work at this level of social responsibility.

Like others ${ }^{5354}$ we found feedback of objective data more effective for many working class patients than exhortation, apparently overcoming cultural barriers that commonly obstruct health education. New, less formal approaches to counselling are needed for primary care. Changes in patient behaviour required to reduce smoking, obesity, high blood cholesterol concentration, and problems with alcohol require more time, differently used, for which few doctors or nurses are prepared in training. Though greater flexibility of staffing is promised in the new contract, cash limited health authority budgets imply that few practices will actually get the new people they need.

Continuity, not salesmanship, will be the keystone of the applied medical science of the future, in which health workers and patients will work together to produce better health not as adversarial providers and consumers but as mutually respectful experts in the realities of care, measuring costs in real currencies of time and measured outcomes rather than the mindless reductionism of the market.

We should keep two legs on the ground. The first will be clinical audit, reported back to patients in local communities through annual reports, which could become an important and positive feature of the contract if developed imaginatively, to be read and acted on by local populations rather than filed away by bureaucrats. The second must remain direct assessibility to the demands of our patients, however irrelevant these may sometimes seem; a right to see your own doctor for 10 minutes is a foundation for participative democracy and our only guarantee of relevance.

Research and innovation in Glyncorrwg began in 1967 and continued without outside support until 1974. Since then we have been helped generously by the MRC Epidemiology and Medical Care Unit at Northwick Park, directed by Dr T W Meade, the British Heart Foundation, King Edward's Hospital Fund, the Wellcome Foundation, and the Rudolf Friedlander Trust. We thank Mr Plunkett, general manager of West Glamorgan Family Practitioner Committee, for data on health promotion clinics, and Helen Wilkes for statistical advice. The conclusions are our own, and do not represent those of the MRC.

1 Catford JC, Ford S. On the state of the public ill-health: premature mortality in the United Kingdom and Europe. BMF 1984;289: 1668-70.

2 Department of Health and Social Security. Inequalities in health. London: DHSS, 1980. (Black report.)

3 Marmot MG, Shipley MJ, Rose G. Inequalities in death: specific explanations of a general pattern? Lancet 1984; i: 1003-6.

4 Smith GD, Bartley M, Blane D. The Black Report on socioeconomic inequalities in health: 10 years on. BMf 1990;301:373-7.

5 Hart JT. The inverse care law. Lancet 1971;i:405-12.

6 Bosanquet N, Leese B. Family doctors and innovation in general practice. $B M \mathcal{J}$ 1988;296:157-80.

7 Leese B, Bosanquet N. High and low incomes in general practice. $B M \mathcal{J}$ 1989;298:932-4.

8 Pringle $M$. The quality divide in primary care. BMf 1989-299:470-1.

9 Main J, Main P. Problematical models - targets and clinics. RCGP Connection 1990; September:4-5.

10 Hayes TM, Harries TJ. Randomised controlled trial of routine hospital clinic care versus routine general practice care for type II diabetes. $B M \mathcal{J}$ 1984;289:728-30.

11 Day TJL, Humphreys H, Alban-Davies H. Problems of comprehensive shared diabetes care. BM7 1987;294:1590-2.

12 Smith WCS, Lee AJ, Crombie JK, Tunstall-Pedoe $\mathrm{H}$, Control of blood pressure in Scotland: the rule of halves. $B M 7$ 1990;300:981-3.

13 Littlepage BNC. Study of small area statistics in West Glamorgan. Swansea: West Glamorgan Health Authority, 1988. (Report to district medical committee.)

$14 \mathrm{Kaul} \mathrm{SA}$, Thomas C. Study of small area statistics in West Glamorgan. Swansea: University of Swansea, 1988.
15 Hart JT. General practice workload, needs and resources in the National Health Services. $7 R$ Coll Gen Pract 1976;26:885-92.

16 Hart JT. Semicontinuous screening of a whole community for hypertension. Lancet 1970;ii:223-6.

17 Hart JT. The marriage of primary care and epidemiology: continuous anticipatory care of whole populations in a state medical service. IR Coll Phys Lond 1974;8:299-314.

18 Hart JT, Humphreys C. Be your own coroner: an audit of 500 consecutive deaths in a general practice. $B M \mathcal{Y} 1987 ; 294: 871-4$.

19 Hart JT. Measurement of omission. BMJ 1982;284:1686-9.

20 Stott $\mathrm{NCH}$, Davies RH. The exceptional potential in each primary care consultation. $\mathcal{F}$ R Coll Gen Pract 1979;29:201-5.

21 Kark SL. The practice of community-oriented primary health care. New York: Appleton-Century-Crofts, 1989

22 Royal College of General Practitioners. Alcohol-a balanced view. London: RCGP, 1986. (Report from general practice No 24.)

23 Wallace PG, Brennan PJ, Haines AP. Drinking patterns in general practice patients. $\mathcal{f} R$ Coll Gen Pract 1987;37:354-7.

24 Watt GCM, Edwards C, Hart JT, Hart M, Walton P, Foy CJW. Dietary sodium restriction for mild hypertension in general practice. $B M \mathcal{Y}$ 1983;286:432-6

25 Watt GCM, Foy CJW, Hart JT. Comparison of blood pressure, sodium intake, and other variables in offspring with and without at family history of high blood pressure. Lancet 1983; i:1245-8.

26 Watt GCM, Foy CJW, Hart JT, Bingham G, Edwards C, Hart M, et al. Dietary sodium and arterial blood pressure: evidence against genetic susceptibility. BMF 1985;291:1525-8.

27 Coope J. A screening clinic for hypertension in general practice. f $R$ Coll Gen Pract 1974;24:161-6.

28 Hamilton $M$, Thompson $\mathrm{EN}$, Wisniewski TKM. The role of blood pressure control in preventing complications of hypertension. Lancet 1964;i:235-8.

29 Veterans Administration Co-operative Group on Antihypertensive Agents. Effects of treatment on morbidity in hypertension II: results in patients with Effects of treatment on morbidity in hypertension II: results in patients with
diastolic pressures averaging 90 through $114 \mathrm{~mm} \mathrm{Hg}$. FAMA 1970;213: diastolic pres $1143-52$.

30 Medical Research Council Working Party. MRC trial of treatment of mild hypertension: principal results. BMJ 1985;291:97-104.

31 Hart JT. Hypertension: community control of high blood pressure. London: Churchill Livingstone, 1987

32 Hart JT. Prevention of coronary heart death in general practice. Postgrad Med J 1984;60:42-6.

33 Directorate of the Welsh Heart Programme. Pulse of Wales: social survey supplement. Cardiff: Heartbeat Wales, 1987. (Heartbeat report No 7.)

34 Directorate of the Welsh Heart Programme. Take heart: a consultative documen on the development of community-based heart health initiatives within Wales. Cardiff: Heartbeat Wales, 1985. (Heartbeat report No 1.)

35 Russell MAH, Wilson C, Taylor C, Baker CD. Effect of general practitioners' advice against smoking. $B M \mathcal{O} 1979$;ii:231-5.

36 Townsend $\mathrm{P}$, Phillimore $\mathrm{P}$, Beattie A. Health and deprivation: inequality and the North. Beckenham: Croom Helm, 1988.

37 Pill R, French J, Harding K, Stott N. Invitation to attend a health check in a general practice setting: comparison of attenders and non-attenders. I $R$ Coll Gen Pract 1988; 38:53-6.

38 Pill $\mathrm{R}$, Stott $\mathrm{N}$. Invitation to attend a health-check in a general practice setting: the views of a cohort of non-attenders. $f R$ Coll Gen Prac 1988;38:57-60

39 Thompson NF. Inviting infrequent attenders to attend for a health check: costs and benefits. British foumal of General Practice 1990;40:16-8.

40 Waller D, Agass M, Mant D, Coulter A, Fuller A, Jones L. Health checks in general practice: another example of inverse care? BMf 1990;300:1115-8.

41 Robson J, Boomla K, Fitzpatrick S, Jewell AJ, Taylor J, Self J, et al. Using nurses for preventive activities with computer assisted follow up: randomised controlled trial. BMF 1989-298:433-6.

42 Hart JT. Reactive and proactive care: a crisis. British fournal of Generol Practice 1990;40:4-9.

43 Hart JT, Stilwell B, Gray JM. Prevention of coronary heart disease and stroke: workbook for primary care teams. London: Faber and Faber, 1988.

44 Ballard DJ, Strogatz DS, Wagner EH, Siscovick DS, James SA, Kleinbaum DG et al. Hypertension control in a rural southern community: medical proces and dropping out. Am F Prev Med 1988;4:133-9.

45 Buchan IC, Richardson IM. Time study of consultations in general practice. Edinburgh: Scottish Home and Health Department, 1973. (Scottish health studies 27 .

46 Morrell DC, Evans ME, Morris RW, Roland MO. The "five minute" consultation: effect of time constraint on clinical content and patien satisfaction. $B M$ F 1986;292:870-3.

47 Ridsdale L, Carruthers M, Morris R, Ridsdale J. Study of the effect of time availability on the consultation. $\mathcal{F} R$ Coll Gen Pract 1989;39:488-91.

48 Thomas K, Birch S, Milner P, Nicholl J, Westlake L, Williams B. Estimates of general practitioner workload a review. $7 R$ Coll Gen Pract 1989:39.509-13. Ridsdale L. General practitioners' workload BMY 1990;301:455-6.

50 Savage R, Armstrong D. Effect of a general practitioner's consulting style on patients' satisfaction: a controlled study. $B M \mathcal{J} 1990 ; 301: 968-70$.

51 Amiel S, Bennett J, Dickinson C, Heath I, Keeley D, Miller R. Health promotion in general practice. BMF 1991;302:527.

52 Al-Bashir MM, Armstrong D. Preferences of healthy and ill patients for style of general practitioner care: implications for workload and financial incentives under the new contract. British fournal of General Practice 1991;41:6-8.

53 Jamrozik K, Vessey M, Fowler G, Wald N, Parker G, Van Vunakis G. Controlled trial of three different smoking interventions in general practice. $B M \mathcal{J} 1984 ; 288$ : 1499-503.

54 Wallace P, Cutler S, Haines A. Randomised controlled trial of gener practitioner intervention in patients with excessive alcohol consumption. BMF 1988;297:663-8.

(Accepted 17 April 1991) 